\title{
Ultrasonography as an educational tool for students - any progress?
}

\author{
Sorin M. Dudea
}

Four years ago, this journal dedicated wide space to the use of ultrasonography as an educational tool. The papers then published by Mircea et al [1] and Fodor et al [2] earned high recognition, as shown by the number of citations. What happened in the meanwhile?

In 2014, in the US, a group of specialists from the Society of Radiologists in Ultrasound and the Alliance of Medical School Educators in Radiology published a paper suggesting a National ultrasound curriculum for medical students [3]. This year, EFSUMB published a position paper on medical student education in ultrasound [4]. Recently, another paper appeared, describing the early experience of a Pilot Point-of-Care Ultrasound Curriculum at Harvard Medical School [5]. During this fall's 28th Euroson Congress in Leipzig, not only were there three sessions dedicated to ultrasound education, of which one was focused exclusively on students, but there were also dedicated practical skills sessions dealing with various basic ultrasound applications, again for students. All the recent publications and approaches are showing an internationally increasing awareness and interest for one of the, possibly, most important, yet highly underused, applications of ultrasonography.

As most countries included specialty - specific ultrasonography in the residency programs, it is only natural (and logical) that basic knowledge on ultrasonography should be acquired during undergraduate medical education. While sonographer students receive a comprehensive training, the ultrasonography education of medical students is highly variable not only among countries but also among medical schools in the same country.

Without aiming to repeat an excellent plea published in an editorial in this journal [6], it is time to realize that

Received Accepted

Med Ultrason

2016, Vol. 18, No 4, 417-418

Corresponding author: Sorin M. Dudea

Radiology Department, Cluj-Napoca County University

Emergency Hospital,

Radiology Desk, "Iuliu Hatieganu" University of Medicine and Pharmacy,

3-5 Clinicilor street, 400006 Cluj-Napoca,

Romania,

Email: sdudea@umfcluj.ro ultrasonography is destined to democratization. More and more professionals are using it in the daily routine; simple, inexpensive, portable machines are readily available. And the benefits, not only for the clinical practice but also as a teaching instrument, are obvious, as summarized by Mircea et al [1]. Basically, ultrasonography is an excellent teaching tool inviting us: use me!

Since benefits are so obvious, why the reluctance and the slow penetration of US in the medical curricula? An analysis of the hindering factors might also prove useful.

Mistrust of academic managers might be one explanation for dragging. This, in its turn, is fed by the lack of large scale, multicentric studies on the usefulness of a curricular change. Indeed, most available studies show only that "most students agree that additional US teaching should be incorporated throughout the (...) medical school curriculum"[5]. While, as suggested, ultrasound may increase self confidence and reduce learning time [2], there still are no large scale studies to prove that students using ultrasound-incorporated curriculum become, at one point of their professional evolution, better doctors. And probably this is not the goal to be aimed at by a modified curriculum. At this point, it is safer to expect from the students greater interest for the learning process, higher self confidence and, in the end, if not better, then definitely smarter doctors.

Financial constraints are another factor to be addressed. Reluctance to change the curriculum may also be linked to the need of purchasing sizeable amounts of equipment. Again, with feeble scientific evidence of palpable results.

In this still slow moving environment, it is noteworthy that the student initiative may set the pace. Originally started in the Medical University in Vienna, the initiative Sono4you, as recently presented in Leipzig, is focused on voluntary peer-based education: "by the students, for the students". Started in 2007 and institutionally sustained, the initiative spreads today in seven academic sites. A similar model was reported in the US, as well [7]. As a recognition of their importance, several ultrasound societies instituted students working groups: DEGUM, the 
German Society for Ultrasound in Medicine, has a students working group and so does, since the Congress in Leipzig, EFSUMB.

However, the medical school initiative should finally be the decisive factor. Beyond well known and praised achievements in the US and already longstanding experience in Vienna and other several German speaking universities, other countries such a Denmark and Poland emerge in this continuous evolving picture.

The initiative of EFSUMB, shaped in a coherent and bold strategy and described in a detailed manner [8], along with available teaching materials, such as the EFSUMB course book, student edition - all freely available! - should represent a solid foundation for all those willing to bring a change, looking into the future of medical student education.

\section{References}

1. Mircea PA, Badea R, Fodor D, Buzoianu AD. Using ultrasonography as a teaching support tool in undergraduate medical education - time to reach a decision. Med Ultrason 2012;14:211-216.

2. Fodor D, Badea R, Poanta L, Dumitraşcu DL, Buzoianu AD , Mircea PA. The use of ultrasonography in learning clinical examination- a pilot study involving third year medical students. Med Ultrason 2012;14:177-181.

3. Baltarowich OH, Di Salvo DN, Scoutt LM, et al. National ultrasound curriculum for medical students. Ultrasound Q 2014;30:13-19.

4. Cantisani V, Dietrich CF, Badea R, et al - EFSUMB statement on medical student education in ultrasound [short version] - Ultraschall in Med 2016;37:100-102.

5. Rempell JS, Saldana F, DiSalvo D, et al. Pilot Point-of-Care Ultrasound Curriculum at Harvard Medical School: Early Experience. West J Emerg Med 2016;17:734-740.

6. Badea R. Medical education of students and residents - a new paradigm? Med Ultrason 2012;14:175-176.

7. Dubosh NM, Kman N, Bahner D. Ultrasound interest group: a novel method of expanding ultrasound education in medical school. Crit Ultrasound J 2011;3:131-134.

8. Cantisani V, DietrichCF, Badea R, et al. EFSUMB statement on medical student education in ultrasound [long version]. Ultrasound Internat Open 2016;2:E2 - E7. 